\title{
Is the Duration of Temozolomide Predictive for Sequential Bevacizumab Treatment Responses in the Glioblastoma Multiforme Cancer Setting?
}

\author{
Mehmet Besiroglu ${ }^{1}$, Tarik Demir ${ }^{2}$, Abdallah T.M. Shbair ${ }^{1}$, Ayse Irem Yasin ${ }^{1}$, Atakan Topcu ${ }^{1}$ and Haci Mehmet \\ Turk $^{1}$ \\ ${ }^{1}$ Department of Medical Oncology, Bezmialem Vakıf University, Istanbul, Turkey \\ ${ }^{2}$ Department of Medical Oncology, Haydarpasa Numune Health Application and Research Center, Istanbul, Turkey
}

\begin{abstract}
Objective: To evaluate the predictive significance of the duration of temozolomide (TMZ) in patients with glioblastoma multiforme (GBM) who were treated with bevacizumab (Beva) as second-line setting.

Study Design: Descriptive study.

Place and Duration of Study: Bezmialem Vakif University School of Medicine Hospital, Istanbul, Turkey, from January 2014 to September 2020.

Methodology: A total of 109 patients, 47 (43.1\%) females and $62(56.9 \%)$ males, were retrospectively included in the study. All patients received TMZ as first-line and Beva as second-line treatment. Kaplan-Meier method and Cox regression model were performed for survival and univariate/multivariate analyses, respectively.

Results: Patients treated with first-line TMZ were divided into two groups according to the PFS. Group 1 is $<9$ months and group 2 is $\geq 9$ months. Overall survival (OS) of group 1 and group 2 patients was evaluated after the initiation of second-line bevacizumab treatment. The OS in group 1 was 7.8 months $(6.9-8.6,95 \% \mathrm{Cl})$, and group 2 was eight months $(6.4-9.5,95 \% \mathrm{Cl})$, but it was statistically non-significant $(p=0.837)$.

Conclusion: Duration of first-line TMZ treatment was not a predictor for OS of the GBM patients, who were treated with Beva as second-line setting.
\end{abstract}

Key Words: Bevacizumab, Duration of treatment, Glioblastoma multiforme, Predictive score, Temozolomide.

How to cite this article: Besiroglu M, Demir T, Shbair AT, Yasin Al, Topcu A, Turk HM. Is the Duration of Temozolomide Predictive for Sequential Bevacizumab Treatment Responses in the Glioblastoma Multiforme Cancer Setting?. J Coll Physicians Surg Pak 2021; 31(08):932-936.

\section{INTRODUCTION}

Glioblastoma multiforme (GBM) is a lethal malignancy with poor prognosis. ${ }^{1}$ The primary treatment of GBM patients is gross total resection and adjuvant radiotherapy (RT) plus temozolomide (TMZ). ${ }^{2}$ Palliative systemic treatments are used in GBM patients for whom local treatments are not appropriate, but options are limited. TMZ is the only option in first-line systemic therapy, if the patient progresses after a long adjuvant interval. Furthermore, in GBM patients, who progressed with TMZ treatment, it is mostly recommended to use bevacizumab (Beva) with or without cytotoxic chemotherapy (CT) in second-line treatment. ${ }^{3}$ Despite all of these aggressive treatments, satisfactory survival results have not been achieved in GBM patients. ${ }^{4}$

Correspondence to: Dr. Mehmet Beşiroğlu, Department of Medical Oncology, Bezmialem Vakıf University, Istanbul,

Turkey

E-mail: besiroglumehmet@gmail.com

Received: January 30, 2021; Revised: June 15, 2021;

Accepted: July 14, 2021

DOI: https://doi.org/10.29271/jcpsp.2021.08.932
Beva is a humanised antibody binding to vascular endothelial growth factor (VEGF). ${ }^{5}$ Beva ( $10 \mathrm{mg} / \mathrm{kg}$ every two weeks) shows approximately $40 \%$ radiological response in patients with GBM; and provides a significant improvement in patients' quality of life. However, despite all these positive effects, it does not prolong OS of newly diagnosed or recurrent GBM patients. ${ }^{6}$ Beva treatment also has many cardiovascular (hypertension, thromboembolism, and left ventricular dysfunction) and non-cardiovascular (proteinuria, delayed wound healing, and bleeding) side effects. ${ }^{7}$

Many factors related to the treatment resistance of Beva have been defined. Still, this issue has not yet been fully clarified; and today, there is no established marker predicting Beva's response. ${ }^{8}$ However, the detection of Beva's predictive markers is vital for optimising individualised therapy. Thus, the treatment costs and unnecessary side effects can be reduced.

Studies show that the duration of first-line treatment is predictive for sequential treatment responses in many cancer types settings. For example, the duration of first-line therapy in prostate and gastric cancer patients is predictive for the second-line treatment duration. ${ }^{9,10}$ However, the predictive significance of 
TMZ treatment duration for Beva in GBM patients is not well known.

The aim of this study was to analyse whether that long initial response to TMZ could predict response to subsequent therapy with Beva in patients with GBM.

\section{METHODOLOGY}

In this descriptive study, archived records between January 2014 and September 2020 for all GBM patients in Bezmialem Vakif University Hospital, Turkey, were used. Criteria of eligible patients, who completed two series of treatments including TMZ and Beva, aged 18 to 80 years, having a histologically proven GBM (except anaplastic astrocytoma and anaplastic oligodendroglioma), and follow-up available with apporpriate imaging technique were included. The exclusion criteria were patients who were not in the follow-up.

All patients underwent maximal safe resection. Following surgery, have treated with concurrent RT (total dose: 60 or 70 $\mathrm{Gy}$ ) and TMZ ( $75 \mathrm{mg} / \mathrm{m}^{2} /$ day). All patients received six cycles of maintenance TMZ ( 150 or 200 mg, for five days every 28 days) after completed chemoradiotherapy treatment. In the first-line treatment, TMZ ( 150 or $200 \mathrm{mg} / \mathrm{m}^{2}$ ) for five days every 28 days' treatment was continued until progression or intolerance in patients, who were notsuitable for surgery and RT after progression and who progressed six months after adjuvant therapy. If there were no symptoms, the patients were followed every three months with a gadolinium-enhanced magnetic resonance (MRI). Patients with symptoms were evaluated immediately. Beva was started as second-line therapy in patients with clinical progression, with or without radiological progression evidence by MRI. Beva $\left(10 \mathrm{mg} / \mathrm{Kg}^{2}\right)$ for every two weeks of treatment was continued until progression in the second-line treatment.

SPSS for Windows, Version 24.0 (SPSS Inc., Chicago, IL, USA) was used for statistical analysis. Quantitative and qualitative variables were given as median and range, mean \pm standard deviation, and frequency and percentage, respectively. Normality analysis of the data was performed using the Kolmogorov-Smirnov test. Treatment response levels were compared with the Chi-square $\left(\mathrm{x}^{2}\right)$ testfor thetwo groups. Correlation analyses were performed using Spearman's correlation analysis since the data did not conform to normal distribution. Survival analysis was performed using the Kaplan-Meier method and compared by the log-rank test. Cox regression analysis was performed for univariate and multivariate analysis, and hazard ratios (HR) with $95 \%$ confidence intervals $(\mathrm{Cl})$ were used to measure indices predicting survival. A value of $p<0.005$ was considered statistically significant.

\section{RESULTS}

A total of 109 patients with GBM were identified in the institutional database. Sixty-two (56.9\%) patients were males, and $43.1 \%(n=47)$ patients were females. The mean age of the patients was $48.6 \pm 12.5$ years. Seventy-four (67.9\%) patients' eastern cooperative oncology group performance score (ECOGPS) was $0-1$ at the time of diagnosis. Thirty-five (32.1\%), patients' ECOG-PS was $>1$. The most common localisations were frontal lobe $(32.1 \%$, 35); temporal lobe $(28.4 \%, 31)$; parietal lobe $(20.2 \%, 22)$; and others $(19.3 \%, 21)$. Primary GBM developed in $89.9 \%$ (98) patients, and GBM secondary to low-grade glioma developed in $10.1 \%$ (11) patients. Ki-67 was $\leq$ $20 \%$ in 62 patients (56.9\%), and Ki-67 was $>20 \%$ in 47 patients (43.1\%). P53 mutation was detected in 57 patients (52.3\%). IDH mutation was detected in 21 patients (23.1\%). Surgery was performed on 98 patients. Total excision was performed in 73 patients $(74.5 \%)$ and subtotal excision in 25 patients $(25.5 \%)$. Total excision was performed in $75.8 \%, 68.4 \%, 83.3 \%$, and $55.6 \%$ of patients with GBM located in the frontal, parietal, temporal, and other lobes, respectively $(p=0.071)$. All of the patients evaluated received RT. While eight of these patients (7.3\%) received RT alone, 103 patients $(92.7 \%)$ received TMZ plus RT. After progression, 15 of the patients (13.8\%) received re-TMZ treatment. All patients, who progressed after TMZ, received Beva treatment. After the first progression, 23 (21.1\%) of the patients received gamma knife treatment(Tablel).

All patients received TMZ as first-line systemic therapy. The impact of age ( $<50$ and $\geq 50$ years), tumour localisation, resection type (total excision or partial resection), ki-67, p53 and IDH-1 status on treatment response were evaluated in patients who treated with temozolomide. In patients who received first-line TMZ, 36.7\% (40), 24.8\% (27), 38.5\% (42) had objective response (OR) (6.4\% complete response (CR), 30.3\% partial response (PR)), stable disease (SD), progressive disease (PD), respectively. Median progression-free survival (PFS) was 8.5 months $(7.0-10.1,95 \% \mathrm{Cl})$. The median duration of the use of TMZ was six months (range: 2-24). Univariate and multivariate analyses were performed to assess the predictive value for PFS in all patients. In univariate Cox regression analysis; gender (HR $0.79(0.54-1.17,95 \% \mathrm{Cl}), \mathrm{p}=0.243)$, age (HR 1.12 (0.77-1.64, $95 \% \mathrm{Cl}$ ), $\mathrm{p}=0.554)$, primary and secondary GBM (HR 0.60 (0.32-1.12, 95\% Cl), $p=0.106)$, Ki 67 level (HR 1.23 (0.84-1.80, $95 \% \mathrm{Cl}$ ), $\mathrm{p}=0.296), \mathrm{p} 53$ mutation status (HR 0.79 (0.54-1.15, $95 \% \mathrm{Cl}), p=0.213$ ) were not found to be associated with survival, while ECOG-PS $>1$ (HR $3.57(2.25-5.64,95 \% \mathrm{Cl})$, $\mathrm{p}<0.001)$, IDH wild type (HR $2.34(1.4-3.91,95 \% \mathrm{Cl}), \mathrm{p}=0.001)$ and subtotal surgery (HR $1.70(1.06-2.71,95 \% \mathrm{Cl}), p=0.028)$ were found to be associated with worse PFS. Multivariate analysis revealed treatment-related IDH-wild (HR 2.28 (1.31-3.96, $95 \% \mathrm{Cl}), \mathrm{p}=0.003)$ and ECOG-PS $>1$ ( HR $=3.79(2.12-6.79,95 \%$ $\mathrm{Cl}), \mathrm{p}<0.001$ ) as independent predictors of worse PFS on TMZbased therapy.

After first-line TMZ treatment progression, 13.8\% (15/109) of the patients received re-temozolomide treatment. All patients received Beva as second-line systemic therapy. In patients who received second-line Beva, 28.4 (31), 31.2\% (34), 38.5\% (42) had OR (2.8\% CR, 25.7\% PR), SD and PD, respectively. Median PFS was five months (3.9-6.1, 95\% Cl). The median duration of the use of TMZ wassix months ( range $=1-62$ ). 
Table I: Demographic features and tumor characteristics of the patients.

\begin{tabular}{|c|c|c|c|}
\hline $\begin{array}{l}\text { Gender } \\
\text { Female } \\
\text { Male }\end{array}$ & $\begin{array}{l}47 / 109(43.1 \%) \\
62 / 109(56.9 \%)\end{array}$ & Age (mean $\pm s d)$ & $48.6 \pm 12.5$ \\
\hline $\begin{array}{l}\text { Age } \\
\leq 50 \\
>50\end{array}$ & $\begin{array}{l}50 / 109(45.9 \%) \\
59 / 109(54.1 \%)\end{array}$ & $\begin{array}{c}\text { ECOG PS } \\
0-1 \\
>1\end{array}$ & $\begin{array}{l}74 / 109(67.9 \%) \\
35 / 109(32.1 \%)\end{array}$ \\
\hline $\begin{array}{l}\text { Tumor localisation } \\
\text { Frontal } \\
\text { Temporal } \\
\text { Parietal } \\
\text { Others }\end{array}$ & $\begin{array}{l}35 / 109(32.1 \%) \\
31 / 109(28.4 \%) \\
22 / 109(20.2 \%) \\
21 / 109(19.3 \%)\end{array}$ & $\begin{array}{l}\text { Type of surgery } \\
\text { Complete resection } \\
\text { Partial resection }\end{array}$ & $\begin{array}{l}73 / 98(74.5 \%) \\
25 / 98(25.5 \%)\end{array}$ \\
\hline $\begin{array}{l}\text { Ki } 67 \\
\leq 20 \\
>20\end{array}$ & $\begin{array}{l}62 / 109(56.9 \%) \\
47 / 109(43.1 \%)\end{array}$ & $\begin{array}{l}\text { P53 status } \\
\text { Mutated } \\
\text { Non mutated }\end{array}$ & $\begin{array}{l}57 / 109(52.3 \%) \\
52 / 109(47.7 \%)\end{array}$ \\
\hline $\begin{array}{l}\text { IDH-1 status } \\
\text { Mutated } \\
\text { Non mutated }\end{array}$ & $\begin{array}{l}21 / 91(23.1 \%) \\
70 / 91(76.9 \%)\end{array}$ & $\begin{array}{c}\text { First line treatment } \\
\text { RT } \\
\text { RT+Temozolamid }\end{array}$ & $\begin{array}{c}8 / 109(7.3 \%) \\
103 / 109(92.7 \%)\end{array}$ \\
\hline $\begin{array}{l}\text { Origin } \\
\text { Primer GBM } \\
\text { Seconder GBM } \\
\end{array}$ & $\begin{array}{l}98 / 109(89.9 \%) \\
11 / 109(10.1 \%)\end{array}$ & $\begin{array}{c}\text { Second line Temozolamid } \\
\text { Present } \\
\text { Absent }\end{array}$ & $\begin{array}{l}15 / 109(13.8 \%) \\
94 / 109(86.2 \%)\end{array}$ \\
\hline $\begin{array}{l}\text { Gamma knife } \\
\text { Present } \\
\text { Absent }\end{array}$ & $\begin{array}{l}23 / 109(21.1 \%) \\
86 / 109(78.9 \%)\end{array}$ & & \\
\hline
\end{tabular}

Table II: The correlation of first line and second line treatment responses.

\begin{tabular}{|c|c|c|c|c|c|}
\hline & & \multirow{2}{*}{\multicolumn{3}{|c|}{ First line temozolamide }} & \multirow{3}{*}{ p-value } \\
\hline & & & & & \\
\hline & & Clinical response & Progressive disease & Total & \\
\hline \multirow{3}{*}{ Second line bevacizumab treatment } & $\begin{array}{l}\text { Clinical } \\
\text { response }\end{array}$ & $53.7 \%(36)$ & $46.3 \%(31)$ & $100 \%(67)$ & \multirow{3}{*}{0.113} \\
\hline & $\begin{array}{l}\text { Progressive } \\
\text { disease }\end{array}$ & $69 \%(29)$ & $31 \%(13)$ & $100 \%(42)$ & \\
\hline & Total & $59.6 \%(65)$ & $40.4 \%(44)$ & $100 \%(109)$ & \\
\hline
\end{tabular}

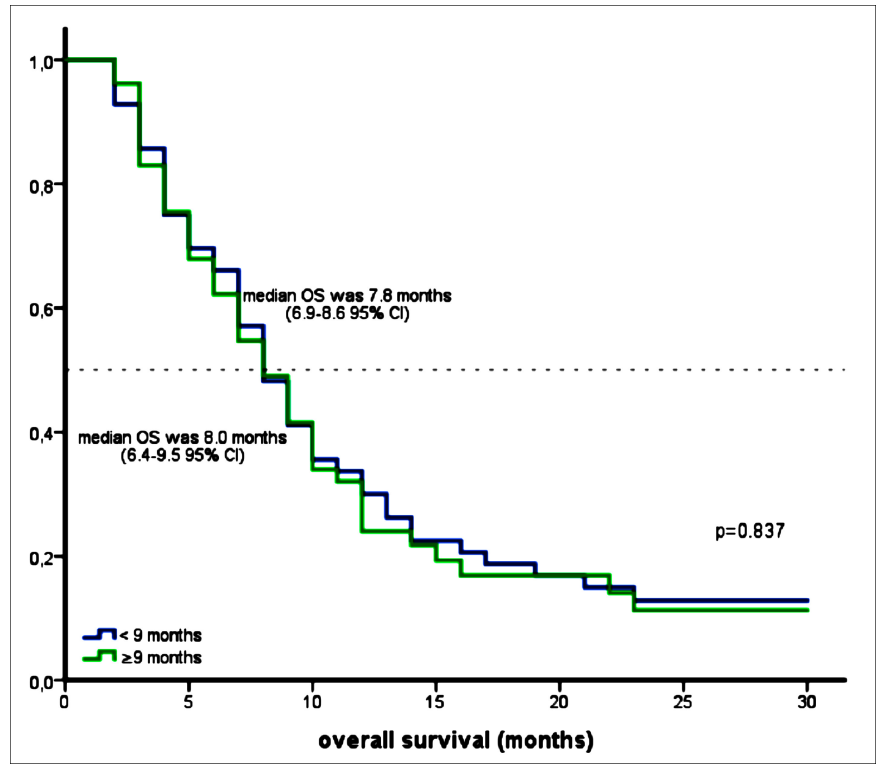

Figure 1: Kaplan-Meier curves according to temozolamid pfs $(<9$ months and $\geq 9$ months) of overall survival with bevacizumab. OS: Overall survival, pfs: Progression free survival.

Univariate and multivariate analyses were performed to assess the predictive value for PFS in all patients. In univariate Cox regression analysis; age (HR 0.88 (0.58-1.33, $95 \% \mathrm{Cl}$ ), $p=0.544)$, gender (HR $1.17(0.78-1.76,95 \%)$, $p=0.447)$, Ki 67 level [HR $1.09(0.73-1.63,95 \% \mathrm{Cl})$, $\mathrm{p}=0.683]$, p53 mutation status (HR $1.03(0.69-1.53,95 \% \mathrm{Cl})$, $\mathrm{p}=0.904)$, IDH mutation status ( $\mathrm{HR} 1.34(0.79-2.30,95 \% \mathrm{Cl})$, $p=0.282)$, re-temozolomide treatment (HR 1.18 (0.65-2.13, $95 \% \mathrm{Cl}), p=0.582)$, clinical response level with temozolomide ( $\mathrm{HR} 0.96(0.63-1.45,95 \% \mathrm{Cl}), \mathrm{p}=0.833)$, and gamma knife treatment (HR $1.67(0.98-2.83,95 \% \mathrm{Cl}), \mathrm{p}=0.058)$ were not found to be associated with survival, while ECOG-PS $>1$ (HR $5.15(3.19-8.32,95 \% \mathrm{Cl}$ ), p<0.001) and subtotal surgery (HR $1.62(1.0-2.62,95 \% \mathrm{Cl}), \mathrm{p}=0.050)$ were found to be associated with worse PFS. Multivariate analysis revealed treatment-related ECOG-PS >1 [HR = 5.21 (3.12-8.70, 95\% $\mathrm{Cl}$ ], $\mathrm{p}<0.001$ ) as independent predictors of worse PFS on Beva-based therapy.

First-line temozolomide treatment showed a clinical response $(O R+S D)$ in $61.5 \%$ of patients, and the clinical response rate with second-line bevacizumab treatment was $59.6 \%$ in these patients. Clinical response rate with second-line bevacizumab treatment was $69 \%(p=0.113)$ in $38.5 \%$ of patients who had no clinical response with temozolomide treatment. The correlation of the first line and second-line treatment responses summarised in Table II.

The patients were divided into two groups according to their first-line TMZ PFS duration (group $1<9$ months and group 2 $\geq 9$ months). The survivals of group 1 and group 2 patients were evaluated after the initiation of second-line bevacizumab treatment. The median os in group 1 was 7.8 months $(6.9-8.6,95 \% \mathrm{Cl})$, and group 2 was 8 months 
(6.4-9.5, 95\% Cl), but it was statistically non-significant ( $p=$ 0.837 , Figure 1 ). No correlation was found in the correlation analysis between temozolomide PFS and OS values after bevacizumab treatment (correlation coefficient $-0.008, \mathrm{p}=$ 0.937).

\section{DISCUSSION}

GBM is a tumor that shows high vascularity; and expresses a very high rate of VEGF-A. In addition, VEGF-A expression is associated with poor survival in GBM patients. ${ }^{11}$ Therefore, the monoclonal anti-VEGF-A antibody Beva was an attractive treatment candidate for GBM patients.

Phase 2 trials showed the OS and PFS benefit of Beva plus $\mathrm{CT}$ in patients with recurrent GBM. However, unlike recurrent GBM, the contribution of Beva to survival in newly diagnosed GBM patients has not been demonstrated in a randomised phase 3 studies. ${ }^{12}$

First-line TMZ and second-line Beva with or without CT are the standard treatment in the daily practice in patients with GBM. Due to the side effects and cost of Beva therapy, it is increasingly important to investigate predictive factors. Many predictive factors have been studied in Beva treatment. Carvalho et al. showed that hypertension and proteinuria are associated with better disease control in Beva treatment of GBM patients. ${ }^{13}$ Vaios et al. showed that the increase in the number of eosinophil, lymphocyte, and platelets in Beva treatment responses of recurrent GBM patients was associated with better clinical response. ${ }^{14}$ In the previously published study, pretreatment inflammatory markers might be an independent predictive marker for patients with GBM who are treated by Beva. ${ }^{15}$ Another study also showed the relationship between high gene expression of angiotensinogen with Beva resistance in recurrent GBM patients. ${ }^{16}$ Surprisingly, although the relationship between the duration of sequential treatments response in many cancer types has been studied, there are no published studies in GBM patients. Dulgar et al. showed the relationship between second-line hormone treatment responses of prostate cancer patients and first-line hormone treatment responses. ${ }^{9}$ In addition, it has been shown that the first-line treatment duration of patients with advanced her2-positive gastric adenocarcinoma and metastatic renal cell carcinoma is predictive for second-line survival benefit. ${ }^{10,17}$ This may be due to the change in the tumor microenvironment, caused by first-line therapy.

Newly diagnosed and recurrent GBM disease is molecularly, genetically, and clinically different. Moreover, GBM can be divided into three groups by transcriptional profiling as classical, proneural, and mesenchymal. The mesenchymal subtype has higher VEGF expression and appears more frequently in recurrent GBM. Therefore, Beva therapy has been shown to be associated with better survival in the GBM mesenchymal subtype. ${ }^{18} \mathrm{~A}$ high genetic mutation burden is also expected in patients with recurrent GBM. For example, TP53 mutation is more common in patients with recurrent GBM compared to newly diagnosed GBM. Moreover, TP53 mutation and IDH1 mutation are more common in proneural GBM patients compared to other groups. The differences between newly diagnosed and recurrent GBM may explain their different responses to Beva treatment. ${ }^{19}$ The authors designed this study considering that TMZ treatment exposure may have a role in this molecular change. Although the authors could not conduct molecular studies in the same patient group, the relationship of these molecular and genetic differences, shown in previous studies with TMZ exposure and its reflection on the Beva response, was exaimed hereby. However, this study showed that the second-line Beva treatment response was not correlated to the first-line TMZ treatment response.

The limitations of this study are its retrospective and single-centre design. The lack of an MGMT result can also be considered a limitation due to its prognostic significance. However, phase 3 studies have shown that MGMT status does not affect the survival benefit of Beva. ${ }^{20}$

\section{CONCLUSION}

In this study, the duration of TMZ was shown not to be predictive for sequential Beva treatment responses in patients with GBM cancer settings. Switching to Beva treatment early may cause the patient to lose benefit from TMZ treatment. Prospective studies with more patients are needed on this subject.

\section{ETHICAL APPROVAL:}

The Clinical Research Ethics Committee of Bezmialem Vakif University approved the study. The ethical approvals were obtained prior to initiation of the research work.

\section{PATIENTS' CONSENT:}

This study was retrospective and covered the years 2014-2020. It was often difficult to reach patients from the previous seven to eight years because some of these patients do not have contact information, and some of them have died. For these reasons, informed consents could not be obtained from the patients.

\section{CONFLICT OF INTEREST:}

The authors declared no conflict of interest.

\section{AUTHORS' CONTRIBUTION:}

MB: Conception, design, supervision, resources, materials, data collection and processing, analysis and interpretation, literature search, writing manuscript, and critical review.

ATMS: Design, supervision, resources, materials, data collection and processing, literature search, writing manuscript, and critical review.

AIY, AT, HMT: Resources, materials, data collection, and processing. 
TD: Conception, design, supervision, resources, materials, data collection and processing, literature search, writing manuscript, and critical review.

\section{REFERENCES}

1. Wen PY, Kesari S. Malignant gliomas in adults. $N$ Engl J Med 2008; 359(5):492-507. doi: 10.1056/NEJMra0708126.

2. Li XZ, Li YB, Cao Y, Li PL, Liang B, Sun DJ, et al. Prognostic implications of resection extent for patients with glioblastoma multiforme: A meta-analysis. J Neurosurg Sci 2017; 61(6):631-9. doi:10.23736/S0390-5616.16.03619-5.

3. NCCN Guidelines, Central Nervous System Cancers. Version 2.2020-April 30, 2020.

4. Korja M, Raj R, Seppä K, Luostarinen T, Malila N, Seppälä M, et al. Glioblastoma survival is improving despite increasing incidence rates: A nationwide study between 2000 and 2013 in Finland. Neuro Oncol 2019; 21(3):370-9. doi: 10.1093/neuonc/noy164.

5. Gatson NN, Chiocca EA, Kaur B. Anti-angiogenic gene therapy in the treatment of malignant gliomas. Neurosci Lett 2012; 527(2):62-70. doi:10.1016/j.neulet.2012.08.001.

6. Friedman HS, Prados MD, Wen PY, Mikkelsen T, Schiff D, Abrey LE, et al. Bevacizumab alone and in combination with irinotecan in recurrent glioblastoma. J Clin Oncol 2009; 27(28):4733-40. doi: 10.1200/JCO.2008.19.8721.

7. Brandes AA, Bartolotti M, Tosoni A, Poggi R, Franceschi E. Practical management of bevacizumab-related toxicities in glioblastoma. Oncologist 2015; 20(2):166-75. doi: 10.1634/ theoncologist.2014-0330.

8. Tamura R, Tanaka T, Miyake K, Yoshida K, Sasaki H. Bevacizumab for malignant gliomas: current indications, mechanisms of action and resistance, and markers of response. Brain Tumor Pathol 2017; 34(2):62-77. doi:10.1007/s10014-017-0284-x.

9. Dülgar Ö, Özyükseler DT, Başak M, Ay S, Tural D, Yıldırım $\mathrm{ME}$, et al. Is the duration of castration resistance predictive for sequential treatment responses in the metastatic castration-resistant prostate cancer setting? J Oncol Pharm Pract 2020; 1078155220951612. doi: 10.1177/1078155220 951612.

10. Barzi A, Hess LM, Zhu YE, Liepa AM, Sugihara T, Beyrer J, et al. Real-world outcomes and factors associated with the second-line treatment of patients with gastric, gastroesophageal junction, or esophageal adenocarcinoma. Cancer Control 2019; 26(1):1073274819847642. doi: 10.1177/ 1073274819847642.

11. Chaudhry IH, O'Donovan DG, Brenchley PE, Reid H,
Roberts IS. Vascular endothelial growth factor expression correlates with tumour grade and vascularity in gliomas. Histopathology 2001; 39(4):409-15. doi:10.1046/ j.1365-2559.2001.01230.x.

12. Chamberlain MC. Bevacizumab for the treatment of recurrent glioblastoma. Clin Med Insights Oncol 2011; 5:117-29. doi: $10.4137 / C M O . S 7232$.

13. Carvalho B, Lopes RG, Linhares P, Costa A, Caeiro C, Fernandes AC, et al. Hypertension and proteinuria as clinical biomarkers of response to bevacizumab in glioblastoma patients. J Neurooncol 2020; 147(1):109-116. doi: 10.1007/s11060-020-03404-z. Epub 2020 Jan 23.

14. Vaios EJ, Winter SF, Muzikansky A, Nahed BV, Dietrich J. Eosinophil and lymphocyte counts predict bevacizumab response and survival in recurrent glioblastoma. Neurooncol Adv 2020; 2(1):vdaa031. doi: 10.1093/ noajnl/vdaa031.

15. Besiroglu M, Shbair AT, Yasin Al, Topcu A, Turk HM, Demir T. Systemic inflammatory markers for prediction of bevaci-zumab benefit in glioblastoma multiforme. J Coll Physicians Surg Pak 2021; 31(1):39-44. doi: 10.29271/jcpsp.2021. 01.39.

16. Urup T, Gillberg L, Kaastrup K, Lü MJS, Michaelsen SR, Andrée Larsen $\mathrm{V}$, et al. Angiotensinogen promoter methylation predicts bevacizumab treatment response of patients with recurrent glioblastoma. Mol Oncol 2020; 14(5):964-73. doi: 10.1002/1878-0261.12660.

17. Ishihara H, Kondo T, Yoshida K, Omae K, Takagi T, lizuka J, et al. Time to progression after first-line tyrosine kinase inhibitor predicts survival in patients with metastatic renal cell carcinoma receiving second-line molecular-targeted therapy. Urol Oncol 2017; 35(9):542.e1-542.e9. doi: 10.1016/ j.urolonc.2017.05.014.

18. Lambrechts D, Lenz HJ, de Haas S, Carmeliet P, Scherer SJ. Markers of response for the antiangiogenic agent bevacizumab. J Clin Oncol 2013; 31(9):1219-30. doi: 10.1200/JC0.2012.46.2762.

19. Verhaak RG, Hoadley KA, Purdom E, Wang V, Qi Y, Wilkerson MD, et al. Cancer genome atlas research network. Integrated genomic analysis identifies clinically relevant subtypes of glioblastoma characterised by abnormalities in PDGFRA, IDH1, EGFR, and NF1. Cancer Cell 2010; 17(1):98-110. doi: 10.1016/j.ccr.2009.12.020.

20. Herrlinger U, Schäfer N, Steinbach JP, Weyerbrock A, Hau P, Goldbrunner R, et al. Bevacizumab plus ırinotecan versus temozolomide in newly diagnosed o6-methylguanine-DNA methyltransferase nonmethylated glioblastoma: The randomized glarıus trial. J Clin Oncol 2016; 34(14):1611-9. doi: 10.1200/JCO.2015.63.4691. 